\title{
DISSOLVING PULP FROM NON-WOOD PLANTS BY PREHYDROLYSIS POTASSIUM HYDROXIDE PROCESS
}

\author{
AKASH MAMON SARKAR, JANNATUN NAYEEM, M. MOSTAFIZUR RAHAMAN and \\ M. SARWAR JAHAN \\ Pulp and Paper Research Division, Bangladesh Council of Scientific and Industrial Research Laboratories, \\ Dhaka, Dr. Qudrat-i-Khuda Road, Dhaka-1205, Bangladesh \\ Corresponding author: M. Sarwar Jahan, sarwar2065@hotmail.com
}

Received April 17, 2020

\begin{abstract}
The garment industry is the backbone of Bangladesh's economy, which imports 30000 metric tons of rayon fiber every year. Bangladesh used to have a rayon plant, but it was shut down a long time ago. At present, the establishment of a new rayon plant in Bangladesh has become an objective. As a forest deficient country, non-wood plants need to be explored for rayon grade dissolving pulp production. Therefore, in this paper, prehydrolysis potassium hydroxide $(\mathrm{KOH})$ pulping process has been investigated for dissolving pulp production from rice and wheat straws, corn stalk, dhaincha and jute stick. The lowest prehydrolysis yield was $70.1 \%$ obtained for corn stalks and the highest prehydrolysis yield was $92.1 \%$ for wheat straw. The $\mathrm{KOH}$ cooking of prehydrolysed rice straw, wheat straw and corn stalks with $14 \%$ alkali charge produced pulps with kappa numbers of 5.7, 4.5 and 8.8, respectively, while prehydrolysed dhaincha and jute stick needed $18 \%$ alkali charge to get a bleachable pulp. Dhaincha showed the highest pulp yield (37.3\%) with the highest $\alpha$-cellulose content $(92.24 \%)$ and the lowest residual pentosan content $(5.37 \%)$. Further purification with cold $\mathrm{KOH}$ extraction increased purity by $3 \%$ for rice straw pulp and by $1 \%$ for dhaincha, wheat straw, corn stalks and jute stick pulp. Thus, the dissolving pulp produced in this study by the prehydrolysis $\mathrm{KOH}$ process can meet the criteria for rayon grade pulp.
\end{abstract}

Keywords: dissolving pulp, prehydrolysis potassium hydroxide process, $\alpha$-cellulose, brightness

\section{INTRODUCTION}

Bangladesh is a small country with high population density and low forest area. The GDP growth rate in Bangladesh is $7.9 \%$, consequently the living standard of people is increasing. ${ }^{1}$ The paper and board consumption in Bangladesh is much lower than the world average, and even compared to the Asian average. To reach Asia's level in terms of paper and board consumption, Bangladesh will have to increase its current consumption tenfold. As the forest resource is very limited in Bangladesh, it is necessary to find alternative fibrous raw materials. Bangladesh is an agricultural country. Total food grains production, according to Bangladesh's Bureau of Statistics (BBS) in 1991-92 was 19.32 million metric tons (MT), which gradually increased to 29.77 million tons in 2007-08, 6.13 percent higher than the previous year's production. Rice, pulses, wheat, potato, tea, maize, sugarcane, cotton, oilseeds etc. are the major crops cultivated in Bangladesh. ${ }^{2,3}$ Rice straw is the most abundant agricultural waste (78.3 million MT), followed by wheat straw ( 2 million MT). ${ }^{3}$ It is also known that the bagasse production after extracting juice from sugarcane is $37 \%$. Based on these data, in Bangladesh there is 1.5 million MT of available bagasse. Maize stalks also reach about 1.5 million MT. Minor crop residues generated in Bangladesh are jute stick, cotton stalk, rapeseed and mustard stalk. These lignocellulosic residues can be considered as alternative raw materials for pulping. However, agricultural based raw materials contain a high amount of silica and fines, which create problems in chemical recovery and machine running in conventional soda and kraft processes.

Considering the problems associated with agricultural wastes pulping, new pulping processes have been proposed, such as organosolv pulping ${ }^{4,5}$ and organic acid pulping. ${ }^{6,7}$ Wheat straw pulping with aqueous ammonia and potassium hydroxide $(\mathrm{KOH})$ was proposed by 
Huang et al., ${ }^{8}$ generating no black liquor waste. The cooking liquor enriched with nutrients, such as potassium and nitrogen, can be used as fertilizer. Rodríguez et al. ${ }^{4}$ investigated rice straw pulping through different processes and obtained the highest pulp yield by the $\mathrm{KOH}$ process. Sun et $a l .{ }^{9}$ reported on corn stover pulping using $\mathrm{KOH}$ and $\mathrm{NH}_{4} \mathrm{OH}$. The combined alkaline system removed $90 \%$ of lignin at the temperature of 150 ${ }^{\circ} \mathrm{C}$ for over $30 \mathrm{~min}$. Recently, our research group has focused on $\mathrm{KOH}$ pulping integrated with the biorefinery concept. ${ }^{10}$ The $\mathrm{KOH}$ spent liquor has been demonstrated to improve soil quality and increase crop production. ${ }^{11}$ The papermaking potential was similar to that of conventional pulping processes. ${ }^{10}$

Dissolving pulp is purified cellulose pulp, which contains the minimum possible hemicelluloses, lignin ash and extractives. ${ }^{12}$ Traditionally, dissolving pulp is produced by prehydrolysis kraft or acid sulfite processes. An alternative pulping technology for dissolving pulp production has also been explored, such as formic acid pulping, where both lignin and hemicelluloses dissolved simultaneously, without affecting cellulose. ${ }^{13-15}$ Sixta et al. ${ }^{16}$ proposed the $\mathrm{SO}_{2}$-ethanol-water ( $\mathrm{SEW}$ ) process to replace the acid sulphite process for the production of rayongrade pulp. Pulp fiber fractionation and alkaline extraction also improved dissolving pulp quality. ${ }^{17}$ No study has been found on dissolving pulp production by the $\mathrm{KOH}$ pulping process.

Therefore, this study investigated the production of dissolving pulp from rice and wheat straws, corn stalk, dhaincha and jute stick by the prehydrolysis potassium hydroxide process. The produced pulps were bleached by $\mathrm{D}(\mathrm{EP}) \mathrm{D}$ stage bleaching. The pulps were also evaluated in terms of cellulose content, alkali solubility and reactivity. To improve the purity of the produced pulp, cold $\mathrm{KOH}$ extraction was also performed.

\section{EXPERIMENTAL \\ Raw materials}

Rice straw, wheat straw, corn stalk, dhaincha and jute stick were collected from the field in the rural area near Dhaka city, and cut to $2-3 \mathrm{~cm}$ in length. After determining the moisture content, air dried raw material equivalent to $300 \mathrm{~g}$ o.d. (oven dried) material was weighed separately in polyethylene bags for subsequent prehydrolysis and cooking experiments.

\section{Prehydrolysis}

Prehydrolysis of rice straw, wheat straw, corn stalk, dhaincha and jute stick was carried out for each separately, in an electrically heated digester of $5 \mathrm{~L}$ capacity. The digester was rotated at $1 \mathrm{rpm}$. Water prehydrolysis was carried out at $150{ }^{\circ} \mathrm{C}$ for rice straw, wheat straw and corn stalk, and at $170{ }^{\circ} \mathrm{C}$ for dhaincha and jute stick, for $60 \mathrm{~min}$. The raw material to liquor ratio was $1: 6(\mathrm{~g} / \mathrm{mL})$. The time required to raise the temperature to the maximum level from room temperature $\left(30{ }^{\circ} \mathrm{C}\right)$ was $35 \mathrm{~min}$. After completing prehydrolysis, the pressure was released by venting the valve and the liquor was separated from the solid mass by filtration and kept in the refrigerator for analysis.

\section{Solids content}

The total solids content in the prehydrolysis liquor (PHL) was determined gravimetrically by drying 10 $\mathrm{mL}$ of sample at $105^{\circ} \mathrm{C}$ until constant weight.

\section{Pulping}

Pulping of prehydrolysed rice straw, wheat straw, corn stalk, dhaincha and jute stick was carried out by the potassium hydroxide $(\mathrm{KOH})$ process in the same digester as in the previous step, under varying $\mathrm{KOH}$ charge $(14,16,16$ and $20 \%$ as $\mathrm{NaOH})$. The following conditions were kept constant:

-Fiber to liquor ratio: 1:5 g/mL;

-Temperature: $150{ }^{\circ} \mathrm{C}$ for rice straw, wheat straw, corn stalk, and $170{ }^{\circ} \mathrm{C}$ for dhaincha and jute stick;

-Cooking time: 120 min at maximum temperature.

After the desired time of cooking, the pulp was cooled, filtered and washed with tap water for the removal of all chemicals, and finally screened in a Flat Vibratory screener, Yasuda, Japan. The pulp yield was determined gravimetrically. The kappa number of the resulting pulp was determined in accordance with Tappi Test Methods (T 236 om-99).

\section{$D_{0}(E P) D_{1}$ bleaching}

Pulps were bleached by $\mathrm{D}_{0}(\mathrm{EP}) \mathrm{D}_{1}$ bleaching sequences in plastic bags. $\mathrm{D}_{0}, \mathrm{D}_{1}$ and EP denote chlorine dioxide in the first stage, chlorine dioxide in the $2^{\text {nd }}$ stage and peroxide reinforced alkaline extraction, respectively. In the first stage $\left(D_{0}\right)$ of $\mathrm{D}_{0} \mathrm{EpD}_{1}$ bleaching sequences, $\mathrm{ClO}_{2}$ charge was $1.5 \%$. The initial $\mathrm{pH}$ was adjusted to 2.5 by adding dilute $\mathrm{H}_{2} \mathrm{SO}_{4}$. In the alkaline extraction stage, $\mathrm{NaOH}$ and $\mathrm{H}_{2} \mathrm{O}_{2}$ charges were $2 \%$ and $0.5 \%$ (on o.d. pulp), respectively. The temperature was $70{ }^{\circ} \mathrm{C}$ for $60 \mathrm{~min}$ and pulp consistency was $10 \%$. In the $\mathrm{D}_{1}$ stage, the end $\mathrm{pH}$ was 4 . The $\mathrm{ClO}_{2}$ charge in $\mathrm{D}_{1}$ was $0.5 \%$.

\section{KOH extraction}

In order to improve the purity of pulp, bleached pulps were extracted with $24 \% \mathrm{KOH}$ (as $\mathrm{KOH}$ ) at 25 ${ }^{\circ} \mathrm{C}$ for $60 \mathrm{~min}$. After extraction, the pulp was filtered and washed with distilled water.

\section{Evaluation of pulps}

Pulp tests were performed according to the Standard Methods of the Technical Association of the 
Pulp and Paper Industry (TAPPI, Atlanta, GA): kappa number (T $236 \mathrm{~cm}-85$ ); brightness (T 452 om-92); viscosity (T 230 om-89), $\alpha$-cellulose (T 203 om-88) and alkali solubility $\mathrm{S}_{10}$ and $\mathrm{S}_{18}$ (T $235 \mathrm{~cm}-85$ ). Fock reactivity was determined according to the modified method described by Tian et al. ${ }^{18}$

\section{RESULTS AND DISCUSSION Prehydrolysis}

Based on previous results, the prehydrolysis of rice straw, wheat straw and corn stalks was carried out at $150{ }^{\circ} \mathrm{C}$ for $1 \mathrm{~h}$, while that of dhaincha and jute stick was carried out at 170 ${ }^{\circ} \mathrm{C}$. ${ }^{19-21}$ The prehydrolysis yield varied from $70.1 \%$ to $92.1 \%$. The lowest prehydrolysis yield was $70.1 \%$ for corn stalks, while the highest yield was achieved for wheat straw (92.1\%). In our earlier study, the prehydrolysis yields of jute stick varied from $72.3 \%$ to $88.6 \%$, depending on the severity of prehydrolysis conditions, as the generated acetic acid also varied from $0.82 \%$ to $1.67 \%$. The $\mathrm{pH}$ of the prehydrolysis liquors also varied from 4.6 to 5.7. A lower $\mathrm{pH}$ was associated with the liberation of acetic acid from the acetyl group of hemicelluloses. The lower yield of corn stalks and the higher yield of wheat straw can be explained by the lower and higher $\mathrm{pH}$ of the PHL, respectively. Thus, more acetic acid was generated during corn stalk prehydrolysis. In hardwoods, hemicelluloses are mainly made up of the xylan backbone of 100-200 xylose units, sometimes branched, and heavily acetylated (6-7 acetyl groups/10 xyloses linked at C-2 and C-3). ${ }^{22}$ Most of the non-wood plants are chemically similar to hardwoods. Therefore, the prehydrolysis of these non-wood plants generated acetic acid similarly to hardwood prehydrolysis. ${ }^{21}$

The organics dissolved from the non-wood plants are represented by the solid content in the prehydrolysis liquor. The sum of solids content in the PHL and prehydrolysis yield should be close to 100 . As shown in Table 1 , the sum was $95.2 \%$, $99.2 \%, 85.8 \%, 92.9 \%$ and $91.7 \%$ for rice straw, wheat straw, corn stalk, dhaincha and jute stick, respectively. The mass balance $<100$ can be explained by volatile organics, which were not determined in this experiment. Similar results were observed in other studies as well. ${ }^{23,24}$

\section{Pulping}

The prehydrolysed rice straw, wheat straw and corn stalk were cooked with varying $\mathrm{KOH}$ charge at $150{ }^{\circ} \mathrm{C}$ for $2 \mathrm{~h}$, while dhaincha and jute stick were cooked at $170{ }^{\circ} \mathrm{C}$ for $2 \mathrm{~h}$ and the results are shown in Table 2. Rice straw, wheat straw and corn stalk delignification was very fast, even under such mild cooking conditions. At 14\% alkali charge, kappa number reached 5.7, 4.5 and 8.8 for rice straw, wheat straw and corn stalk, respectively.

Prehydrolysis increases the porosity of the raw material, partially degrades lignin and cleaves the carbohydrate-lignin bonds, thus improving the delignification of prehydrolysed biomass. ${ }^{12}$ Easier delignification of prehydrolysed raw materials has also been explained by the loosened structure of prehydrolysed wood chips, allowing easier access of the white liquor to the extracted wood chips. ${ }^{25}$ Huang et $a .^{26}$ also reported that xylan preextracted wood chips required lower $\mathrm{H}$-factor and effective alkali to get a similar kappa number to that of the non-extracted wood chips. Lu et al. ${ }^{27}$ also showed that the lower kappa number of xylan pre-extracted aspen wood chips, as opposed to non-extracted wood chips, and the kappa number of the pulps decreased with increasing preextraction time and temperature. The kappa number of wheat straw pulp did not decrease with increasing alkali charge. The pulp yield of rice straw, wheat straw and corn stalks decreased from $32.4 \%$ to $27.7 \%$, from $34.5 \%$ to $29.3 \%$ and from $35.1 \%$ to $28.5 \%$ with increasing alkali charge from $14 \%$ to $20 \%$, respectively. Dhaincha and jute stick behaved differently.

Table 1

Prehydrolysis of non-wood plants

\begin{tabular}{lccc}
\hline \multirow{2}{*}{ Raw material } & Yield & \multicolumn{2}{c}{ Liquor } \\
\cline { 3 - 4 } & $(\%)$ & $\mathrm{pH}$ & Solids content (\%) \\
\hline Rice straw & 86.0 & 5.0 & 9.2 \\
Wheat straw & 92.1 & 5.7 & 7.1 \\
Corn stalk & 70.1 & 4.6 & 15.7 \\
Dhaincha & 80.1 & 4.7 & 12.8 \\
Jute stick & 77.8 & 4.7 & 13.9 \\
\hline
\end{tabular}


Table 2

Potassium hydroxide pulping of non-wood plants

\begin{tabular}{ccccccccccc}
\hline \multirow{2}{*}{$\begin{array}{c}\text { Alkali charge } \\
(\%)\end{array}$} & \multicolumn{2}{c}{ Rice straw } & \multicolumn{3}{c}{ Wheat straw } & \multicolumn{2}{c}{ Corn stalk } & \multicolumn{2}{c}{ Dhaincha } & \multicolumn{2}{c}{ Jute stick } \\
\cline { 2 - 11 } & PY & KN & PY & KN & PY & KN & PY & KN & PY & KN \\
\hline 14 & 32.4 & 5.7 & 34.5 & 4.5 & 35.1 & 8.8 & - & - & - & - \\
16 & 30.9 & 5.4 & 34.3 & 4.4 & 31.6 & 4.8 & $37.3 *$ & 29.3 & $42.1 *$ & 25.3 \\
18 & 29.0 & 5.2 & 31.5 & 4.4 & 29.1 & 3.3 & 37.4 & 9.9 & 33.3 & 19.3 \\
20 & 27.7 & 4.6 & 29.3 & 4.6 & 28.5 & 3.4 & 35.0 & 4.4 & 32.9 & 16.6
\end{tabular}

PY - pulp yield, KN - Kappa number, *Screened rejects $7.8 \%$ in dhaincha and $7.1 \%$ in jute stick are included

Table 3

Bleaching and dissolving pulp evaluation

\begin{tabular}{lccccccc}
\hline Raw material & $\begin{array}{c}\text { Brightness } \\
(\%)\end{array}$ & $\begin{array}{c}\text { Viscosity } \\
(\mathrm{mPa} . \mathrm{s})\end{array}$ & $\begin{array}{c}\alpha \text {-cellulose } \\
(\%)\end{array}$ & $\begin{array}{c}\mathrm{S}_{10} \\
(\%)\end{array}$ & $\begin{array}{c}\mathrm{S}_{18} \\
(\%)\end{array}$ & $\begin{array}{c}\text { Pentosans } \\
(\%)\end{array}$ & $\begin{array}{c}\text { Fock } \\
\text { reactivity }\end{array}$ \\
\hline Dhaincha & 79.5 & 10.32 & 92.24 & 9.14 & 6.21 & 5.37 & 48.82 \\
Corn stalk & 79.7 & 7.37 & 89.22 & 12.33 & 10.54 & 7.58 & 59.25 \\
Jute stick & 85.0 & 10.9 & 90.28 & 9.06 & 8.2 & 6.96 & 50.67 \\
Rice straw & 85.4 & 6.25 & 87.86 & 15.09 & 13.55 & 10.8 & 61.56 \\
Wheat straw & 82.1 & 5.74 & 90.39 & 12.3 & 7.03 & 6.91 & 66.21 \\
\hline
\end{tabular}

At $14 \%$ alkali, the charge pulps were not defibrated. The kappa number of dhaincha and jute stick pulp reached 29.3 and 25.3 with screen rejects of 7.8 and $7.1 \%$, respectively, at $16 \%$ alkali charge; with further increase of the alkali charge to $18 \%$, kappa number suddenly dropped to 9.9 and 19.6, with no rejects, respectively. The pulp yield under this condition was $37.4 \%$ for dhaincha and $33.3 \%$ for jute stick. A similar screened pulp yield was obtained from $\mathrm{Na}_{2} \mathrm{CO}_{3}$ pre-extracted $T$. orientalis at a kappa number of 21-22, where $2 \%$ less alkali was required in cooking. ${ }^{28}$ From the above discussion, it can be said that optimum alkali charge for rice straw, wheat straw and corn stalk was $14 \%$, while for dhaincha and jute stick it was $18 \%$.

\section{Bleaching and pulp evaluation}

Rice straw, wheat straw and corn stalks pulps obtained with $14 \% \mathrm{KOH}$ charge, and dhaincha and jute stick pulps obtained with $18 \% \mathrm{KOH}$ charge were selected for pulp bleaching and evaluation for dissolving pulp. The results are shown in Table 3. The final brightness of rice straw, wheat straw, corn stalk, dhaincha and jute stick reached $85.4,82.1,79.7,79.5$ and $85.0 \%$, respectively. The highest $\alpha$-cellulose content $(92.24 \%)$ and the lowest residual pentosan content $(5.37 \%)$ were found in dhaincha pulp, which was quite acceptable for rayon grade pulp. Rice straw and corn stalk pulps could not reach the desired level of purity $(87.86 \%$ and $89.22 \%)$, where residual pentosan contents were $10.8 \%$ and $7.58 \%$, respectively.

In previous work, dissolving pulp was produced from rice straw with $93.6 \%$ purity, with a given residual pentosan of $5.1 \% .^{29}$ The purity of bleached pulp was dependent on the severity of prehydrolysis and active alkali in cooking. ${ }^{30}$ In an earlier study, the $\alpha$-cellulose content from wheat straw pulp was $97.3 \%$ in the prehydrolysis kraft process. ${ }^{31}$ Corn stalks produced pulp with $94.8 \%$ $\alpha$-cellulose under optimum conditions in the prehydrolysis/kraft pulping with $20 \%$ active alkali, 25\% sulfidity and HEHP bleaching. ${ }^{32}$ Table 3 also shows that jute stick produced dissolving pulp with $90.28 \% \alpha$-cellulose content and a pentosan content of $6.97 \%$. These results were inferior to those found for dissolving pulp produced from jute stick by prehydrolysis at 170 ${ }^{\circ} \mathrm{C}$ for 60 min followed by kraft pulping. ${ }^{21}$

Alkali solubilities $S_{10}$ and $S_{18}$ provide evidence on the low molecular weight carbohydrates (degraded cellulose and hemicelluloses) and hemicelluloses in pulp, respectively. ${ }^{33}$ As shown in Table 3, the highest amount of low molecular weight degraded cellulose $\left(S_{10}-S_{18}\right)$ in the pulp obtained from wheat straw was $5.27 \%$, which was consistent with the lowest viscosity. The $\mathrm{S}_{10}-\mathrm{S}_{18}$ value of pulp obtained from jute cutting-caddis mixture prehydrolysis at $140{ }^{\circ} \mathrm{C}$ was $2-4 \%$ only, while it was $2-8 \%$ for prehydrolysis at $170{ }^{\circ} \mathrm{C} .{ }^{34}$

Dissolving pulp with high purity and controlled viscosity is required for viscose rayon production. High viscosity creates problems 
during the filtration of viscose, while low viscosity results in poor physical strength of rayon products. Therefore, uniform molecular weight distribution and good reactivity are usually preferred. ${ }^{12,35}$ Dhaincha and jute stick pulp presented suitable viscosity (10.32 and 10.9 $\mathrm{mPa} . \mathrm{s})$, while corn stalk, wheat and rice straws showed low viscosities (5.7-7.4 mPa.s). Nayeem et al. $^{34}$ stated that prehydrolysis severity decreased pulp viscosity. However, the prehydrolysis conditions for dhaincha and jute stick in this work were more severe than those applied to corn stalk, wheat straw and rice straw. Thus, the severity of prehydrolysis varied among the raw materials, and it needs to be assessed for each particular raw material.

Fock reactivity measurement of dissolving pulp can simulate the commercial viscose-rayon process very well. ${ }^{18,36}$ Fock reactivity for dhaincha pulp, jute stick, corn stalk, rice and wheat straws was $48.82 \%, 50.67 \%, 59.25 \%$, $61.56 \%$ and $66.21 \%$, respectively. A higher $\mathrm{S}_{10^{-}}$ $\mathrm{S}_{18}$ value may improve accessibility (i.e., the physical ability of reactants/solvents to reach the hydroxyl groups, and to overcome steric hindering in the fiber structure).$^{37}$ Fock reactivity can be increased by enzymatic treatment and refining of the pulp sample. ${ }^{17,38}$

\section{Cold KOH extraction}

Cold alkali extraction is a common procedure for improving pulp purity. ${ }^{12}$ The maximum $\alpha$ cellulose content increased for rice straw pulp from $87.86 \%$ to $90.87 \%$ with $24 \% \mathrm{KOH}$ extraction (Fig. 1). The other pulps increased their purity by about $1 \%$ only. This purity increase can be explained by the dissolution of hemicelluloses in $\mathrm{KOH}$ extraction. In another study, the pentosan content decreased to $9.8 \%$ from $13.7 \%$ by alkaline extraction $(\mathrm{NaOH})$ with $8 \%$ alkali charge at 25 ${ }^{\circ} \mathrm{C}$, which was further decreased to $9.0 \%$ with increasing alkali charge to $12 \% .^{39}$

\section{Proposed biorefinery concept}

The proposed $\mathrm{KOH}$ based integrated biorefinery concept for the production of dissolving pulp from non-wood plants is illustrated in Figure 2. The prehydrolysis of nonwood plants is carried out at high temperature and pressure, where parts of hemicelluloses and lignin are dissolved and acetic acid is generated from the bound acetyl groups of hemicelluloses. ${ }^{20,23}$ Then, the prehydrolysed non-wood plant chips are cooked with $\mathrm{KOH}$ liquor. In the $\mathrm{KOH}$ pulping process, silica and organic biomass constituents are dissolved, which can be then utilized in biobased products development. Silica can be separated from the black liquor by reducing its $\mathrm{pH}$ to 7 by dilute sulfuric acid $\left(\mathrm{H}_{2} \mathrm{SO}_{4}\right){ }^{9}$ The $\mathrm{pH}$ of the prehydrolysis liquor (PHL) is already in the acidic range due to the generated acetic acid. Mixing PHL with $\mathrm{KOH}$ spent liquor will also help reduce the $\mathrm{pH}$ to some extent. In our previous study, $10.4 \%$ silica was precipitated from the black liquor of $\mathrm{KOH}$ pulping of rice straw. ${ }^{9}$ The silica separated from non-wood plants could be purified to higher grades, to enhance the economic benefits of the pulp mill.

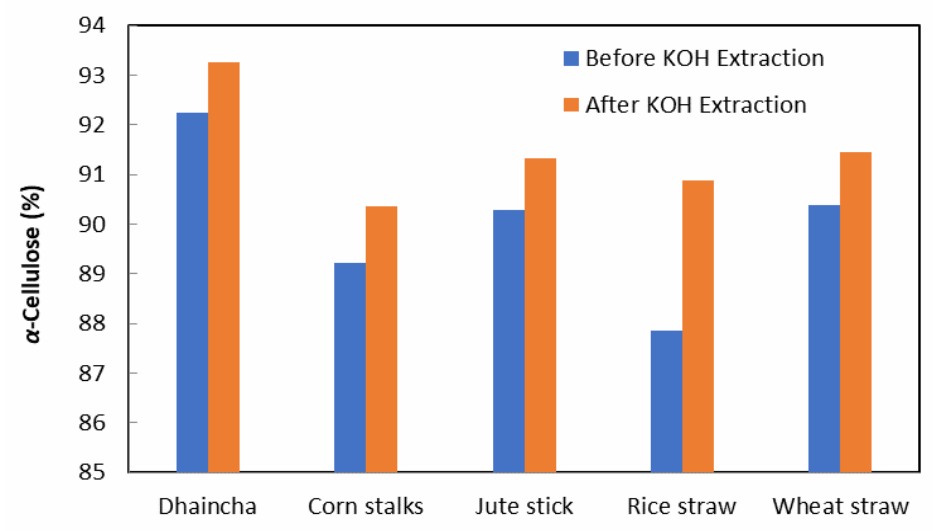

Figure 1: Dissolving pulp purity after $\mathrm{KOH}$ extraction 


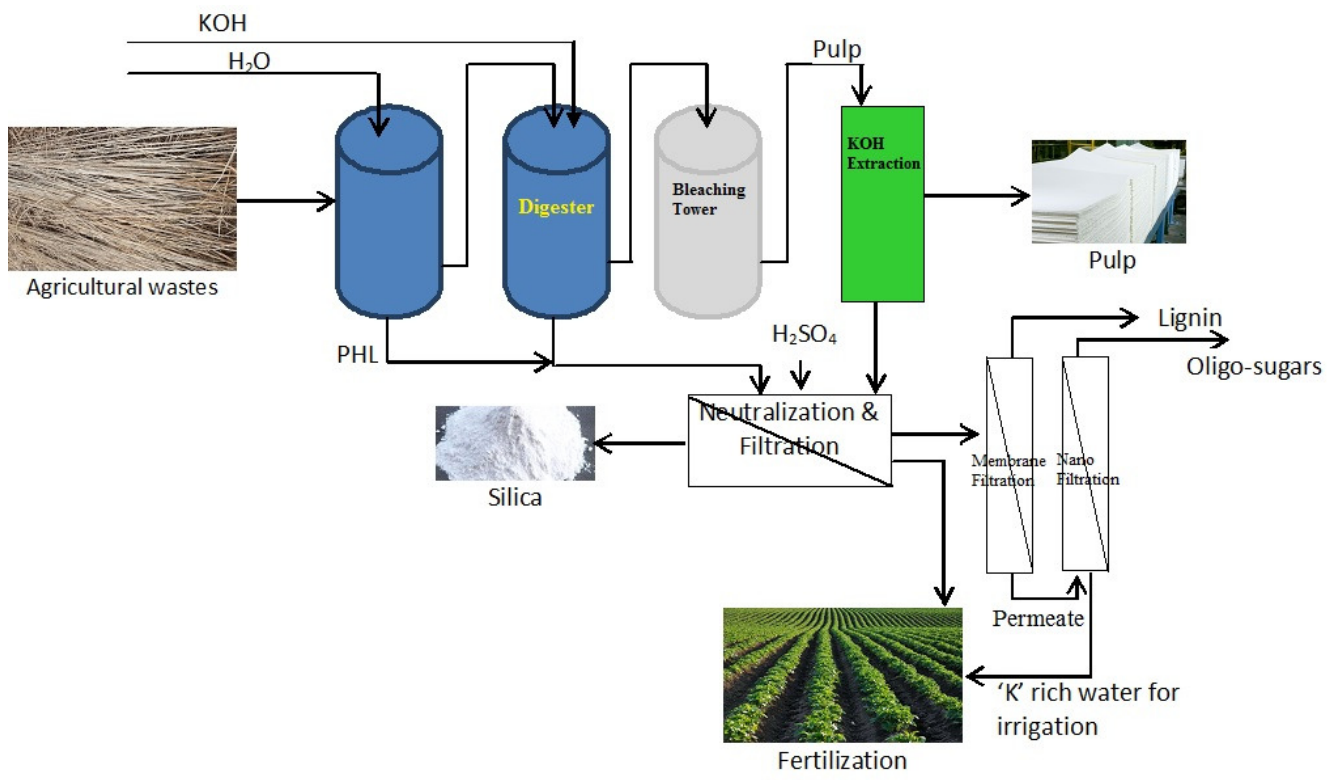

Figure 2: A biorefinery concept for dissolving pulp production from non-wood plants by prehydrolysis $\mathrm{KOH}$ process

Lignin has the ability to improve soil quality. ${ }^{40}$ Lignin was also used in slow release of urea. ${ }^{41}$ Silica separated $\mathrm{KOH}$ spent liquor contains potassium and organics, which can be used for soil amendment (i.e., fertilizer). Lignin can also be used in different high value-added applications, such as the development of renewable polymeric materials. ${ }^{42-44}$ Lignin can be separated by membrane filtration. ${ }^{45,46}$ The PHL and $\mathrm{KOH}$ spent liquor lignin are characterized by higher phenolic hydroxyl group content and lower molecular weight, making it more reactive in resin preparation. ${ }^{47}$ Therefore, many studies have been carried out on lignin-based resin preparation. $^{43-48}$ In addition to lignin, the PHL and $\mathrm{KOH}$ spent liquors contain considerable amounts of carbohydrates (sugars in mono and oligomeric forms), which can be concentrated by nanofiltration. ${ }^{49}$ The sugars in the biorefinery process could be enzymatically and chemically transformed into chemicals and fuel. ${ }^{50-52}$ The supernatant obtained after separating silica and lignin, neutralized with ammonia, was used as soil amendment (i.e., fertilizer). The details of this conversion process will be discussed in a future communication. Therefore, in the proposed crop residue fractionation, nothing will be wasted.

\section{CONCLUSION}

Water prehydrolysis, followed by potassium hydroxide pulping, was performed for dissolving pulp production from rice straw, wheat straw, corn stalk, dhaincha and jute sticks.

In the prehydrolysis, the maximum amount of biomass was dissolved from corn stalk, whereas the lowest - from wheat straw, leaving PHL of the lowest and the highest $\mathrm{pH}$, respectively. Rice straw, wheat straw and corn stalk showed lower chemical requirement for pulping, compared to dhaincha and jute sticks. Dissolving pulp from dhaincha exhibited the best quality in terms of purity and pulp properties. Almost similar quality was found for the dissolving pulps from jute sticks and wheat straw. The purity of dissolving pulps was improved by cold potassium hydroxide treatment.

The most significant element of the proposed biorefinery concept consists in the utilization of the black liquor as fertilizer after separating the biomass step by step for small scale production.

\section{REFERENCES}

1 https://data.worldbank.org/indicator/NY.GDP.MKT P.KD.ZG?locations=BD

2 FAOSTAT, 2016 , http://faostat3.fao.org/download/F/FO/E

3 M. S. Jahan, M. N. Uddin and A. F. M. Akhtaruzzaman, Forest. Chron., 92, 447 (2016), https://doi.org/10.5558/tfc2016-080

4 A. Rodríguez, L. Serrano, A. Moral and L. Jiménez, Biochem. Eng. J., 42, $243 \quad$ (2008), https://doi.org/10.1016/j.bej.2008.07.001 
5 A. A. Shatalov and H. Pereira, Carbohyd. Polym., 67, $275 \quad$ (2007), https://doi.org/10.1016/j.carbpol.2006.05.028

6 M. S. Jahan, Z. Z. Lee and Y. Jin, Turk. J. Agric. For., $\quad 30, \quad 231 \quad$ (2006), https://journals.tubitak.gov.tr/agriculture/abstract.htm?i $\mathrm{d}=8347$

7 A. Seisto and L. Poppius, Tappi J., 80, 215 (1997), https://www.tappi.org

8 G. Huang, J. X. Shi and T. A. Langrish, Bioresour. Technol., $\quad 98, \quad 1218 \quad$ (2007), https://doi.org/10.1016/j.biortech.2006.05.002

9 Y. Sun, G. Yang, J. P. Zhang and M. S. Yao, Chem. Ind. Chem. Eng. Q., 18, 137 (2012), http://scindeks.ceon.rs/article.aspx? artid=145193721202137S

10 M. S. Jahan, F. Haris, M. M. Rahman, P. R. Samaddar and S. Sutradhar, Bioresour. Technol., 219, 445

(2016),

https://doi.org/10.1016/j.biortech.2016.08.008

11 M. S. Jahan, T. Akter, J. Nayeem, P. R. Samaddar and M. Moniruzzaman, J-FOR, 6, 46 (2016), http://www.paptac.ca/en/publications/jfor/658-j-forvolume-6

12 H. Sixta, "Handbook of Pulp", Wiley-VCH, Verlag GmbH and Co., Weinheim, 2006, vol. 1, pp. 511-560

13 M. S. Jahan, S. Rawsan, D. N. Chowdhury and A. Al-Maruf, BioResources, 3, $1359 \quad$ (2008), http://ojs.cnr.ncsu.edu/index.php/BioRes/article/downl oad/BioRes_03_4_1359_Jahan_RNA_Atl_Pulping_Di ssolv_Jute/288

14 M. Sarkar, J. Nayeem, R. S. Popy, A. H. Quadery and M. S. Jahan, Bioresour. Technol. Rep., 4, 96 (2018), https://doi.org/10.1016/j.biteb.2018.09.008

15 S. Sutradhar, M. Sarkar, J. Nayeem, M. S. Jahan and C. Tian, Bangladesh J. Sci. Ind. Res., 53, 1 (2018), https://doi.org/10.3329/bjsir.v53i1.35903

16 H. Sixta, M. Iakovlev, L. Testova, A. Roselli, M. Hummel et al., Cellulose, 20, 1547 (2013), https://doi.org/10.1007/s10570-013-9943-1

17 J. Nayeem, M. Sarkar, A. H. Quadery and M. S. Jahan, Nord. Pulp Pap. Res. J., 32, 620 (2017), https://doi.org/10.3183/npprj-2017-32-04_p620-

629 jahan

18 C. Tian, L. Zheng, Q. Miao, C. Nash, C. Cao et al., $\begin{array}{llll}\text { Tappi } & \text { J., } & \mathbf{1 2}, & 21\end{array}$ https://imisrise.tappi.org/TAPPI/Products/13/NOV/13 NOV21.aspx

19 M. S. Jahan, H. Rahman, P. R. Samaddar and M. Rahman, Bangladesh J. Sci. Ind. Res., 50, 7 (2015), https://doi.org/10.3329/bjsir.v50i1.23804

20 M. S. Jahan and M. M. Rahman, Carbohyd. Polym., 88 583

(2012),

https://doi.org/10.1016/j.carbpol.2012.01.005

21 M. Matin, M. M. Rahaman, J. Nayeem, M. Sarkar and M. S. Jahan, Carbohyd. Polym., 115, 44 (2015), https://doi.org/10.1016/j.carbpol.2014.08.090
22 J. L. Colodette and K. O. Henricson, in "The Bleaching of Pulp", edited by P. W. Hart and A. W. Rudie, 2012, pp. 103-146

23 I. Egüés, C. Sanchez, I. Mondragon and J. Labidi, Bioresour. Technol., 103, $239 \quad$ (2012), https://doi.org/10.1016/j.biortech.2011.09.139

24 A. Saeed, M. S. Jahan, H. Li, Z. Liu, Y. Ni et al., Biomass Bioenerg., $39,14 \quad$ (2012), https://doi.org/10.1016/j.biombioe.2010.08.039

25 W. W. Al-Dajani and W. T. Ulrike, Tappi J., 7, 3 (2008),

https://imisrise.tappi.org/TAPPI/Products/08/JUN/08J UN03.aspx

${ }^{26}$ H. J. Huang, S. Ramaswamy, W. W. Al-Dajani and U. Tschirner, Bioresour. Technol., 101, 624 (2010), https://doi.org/10.1016/j.biortech.2009.07.092

27 H. Lu, R. Hu, A. Ward, T. E. Amidon, B. Liang et al., Biomass Bioenerg., 39, 5 (2012), https://doi.org/10.1016/j.biombioe.2011.01.054

28 M. S. Jahan, M. Sarkar and M. M. Rahman, Drewno, $\quad 58, \quad 69 \quad$ (2015), http://yadda.icm.edu.pl/yadda/element/bwmeta1.eleme nt.agro-79c77a5b-6ff8-465a-872bb8f5c3948405/c/Pages_from_Drewno_195_-_calosc6_69.pdf

${ }^{29}$ M. S. Jahan, S. Sutradhar, M. M. Rahman and M. A. Quaiyyum, Nord. Pulp Pap. Res. J., 30, 562 (2015), https://doi.org/10.3183/npprj-2015-30-04-p562-567

30 M. S. Jahan, L. Ahsan, A. Noori and M. A. Quaiyyum, BioResources, 3, $816 \quad$ (2008), https://ojs.cnr.ncsu.edu/index.php/BioRes/article/down load/BioRes_03_3_0816_Jahan_ANQ_DissolvingPulp _Nalita_Prehyd_Kraft_EDA/228

${ }_{31}$ M. S. Jahan, N. Sultana, M. Rahman and A. Quaiyyum, Biomass Convers. Biorefin., 3, 179 (2013), https://doi.org/10.1007/s13399-012-0067-x

32 J. Behin and M. Zeyghami, Chem. Eng. J., 152, 26 (2009), https://doi.org/10.1016/j.cej.2009.03.024

33 L. P. Christov, M. Akhtar and B. A. Prior, Holzforschung, $\quad \mathbf{5 0}, \quad 579 \quad$ (1996), https://www.fpl.fs.fed.us/documnts/pdf1996/chris96b.p df

34 J. Nayeem, M. S. Jahan, R. S. Popy, M. N. Uddin and M. A. Quaiyyum, Tappi J., 18, 287 (2019), https://imisrise.tappi.org/TAPPI/Products/19/MAY/19 MAY287.aspx

35 E. Kline, in "Cellulose and Cellulose Derivatives", edited by E. Ott, H. M. Spurlin and M. W. Grafflin, New York, Interscience Publishers Inc., 1954, vol 5

36 W. Fock, Papier, 13, 92 (1959)

37 P. Strunk, B. Eliasson, C. Hägglund and R. Agnemo, Nord. Pulp Pap. Res. J., 26, 81 (2011), https://doi.org/10.3183/npprj-2011-26-01-p081-089

38 Q. Miao, L. Chen, L. Huang, C. Tian, L. Zheng et al., Bioresour. Technol., 154, 109 (2014), https://doi.org/10.1016/j.biortech.2013.12.040

39 M. S. Jahan, R. C. Deb, M. M. Rahaman and M. A.

Quaiyyum, Tappi J., 15, $277 \quad$ (2016), 
https://imisrise.tappi.org/TAPPI/Products/16/APR/16A PR277.aspx

40 A. M. Thomsen, U.S. Patent No. 2,663,628. Washington, DC, U.S. Patent and Trademark Office, 1953

${ }^{41}$ M. C. García, J. A. Diez, A. Vallejo, L. Garcia and M. C. Cartagena, Ind. Eng. Chem. Res., 35, 245 (1996), https://doi.org/10.1021/ie950056f

42 N. E. E. Mansouri, A. Pizzi and J. Salvado, J. Appl. Polym. Sci., 103, $1690 \quad$ (2007), https://doi.org/10.1002/app.25098

43 A. J. Ragauskas, G. T. Beckham, M. J. Biddy, R. Chandra, F. Chen et al., Science, 344, 1246843 (2014), https://doi.org/10.1126/science. 1246843

44 M. Sarkar, C. Tian and M. S. Jahan, Tappi J., 17, 63 (2018), https://imisrise.tappi.org/TAPPI/Products/18/FEB/18F EB63.aspx

45 A. Toledano, A. García, I. Mondragon and J. Labidi, Sep. Purif. Technol., 71, 38 (2010), https://doi.org/10.1016/j.seppur.2009.10.024

46 O. Wallberg and A. S. Jönsson, Desalination, 195, 187

(2006),
47 G. Yang, M. S. Jahan and Y. Ni, Curr. Org. Chem., 17, 1589

(2013),

https://www.ingentaconnect.com/content/ben/coc/2013 /00000017/00000015/art00006

48 A. Pizzi and J. Salvadó, Holz Roh. Werkst., 65, 65 (2007), https://doi.org/10.1007/s00107-006-0130-z

49 L. Ahsan, M. S. Jahan and Y. Ni, Bioresour. Technol., 155 , 111 (2014), https://doi.org/10.1016/j.biortech.2013.12.096

50 H. Liu, H. Hu, M. S. Jahan and Y. Ni, Bioresour. Technol., $\quad$ 131, $315 \quad$ (2013), https://doi.org/10.1016/j.biortech.2012.12.158

51 S. Takahashi, K. Tanifuji, K. Shiell, P. Fatehi, M. S. Jahan et al., BioResources, 8, 2417 (2013), http://ojs.cnr.ncsu.edu/index.php/BioRes/article/downl oad/BioRes_08_2_2417_Takahashi_Acetic_Acid_Sulf ite/2059

52 K. Tanifuji, S. Takahashi, K. Shiell, M. S. Jahan, Y. $\mathrm{Ni}$ et al., BioResources, 8, 3912 (2013), http://ojs.cnr.ncsu.edu/index.php/BioRes/article/downl oad/BioRes_08_3_3912_Tanifuji_Ethanol_Fermentati on/2187

https://doi.org/10.1016/J.DESAL.2005.11.011 